rinal Report

on

\section{Natural and Anthropogenic Climate Change}

Grant DE-FG02-86ER60422

(1 March 1986 - 31 August 1992)

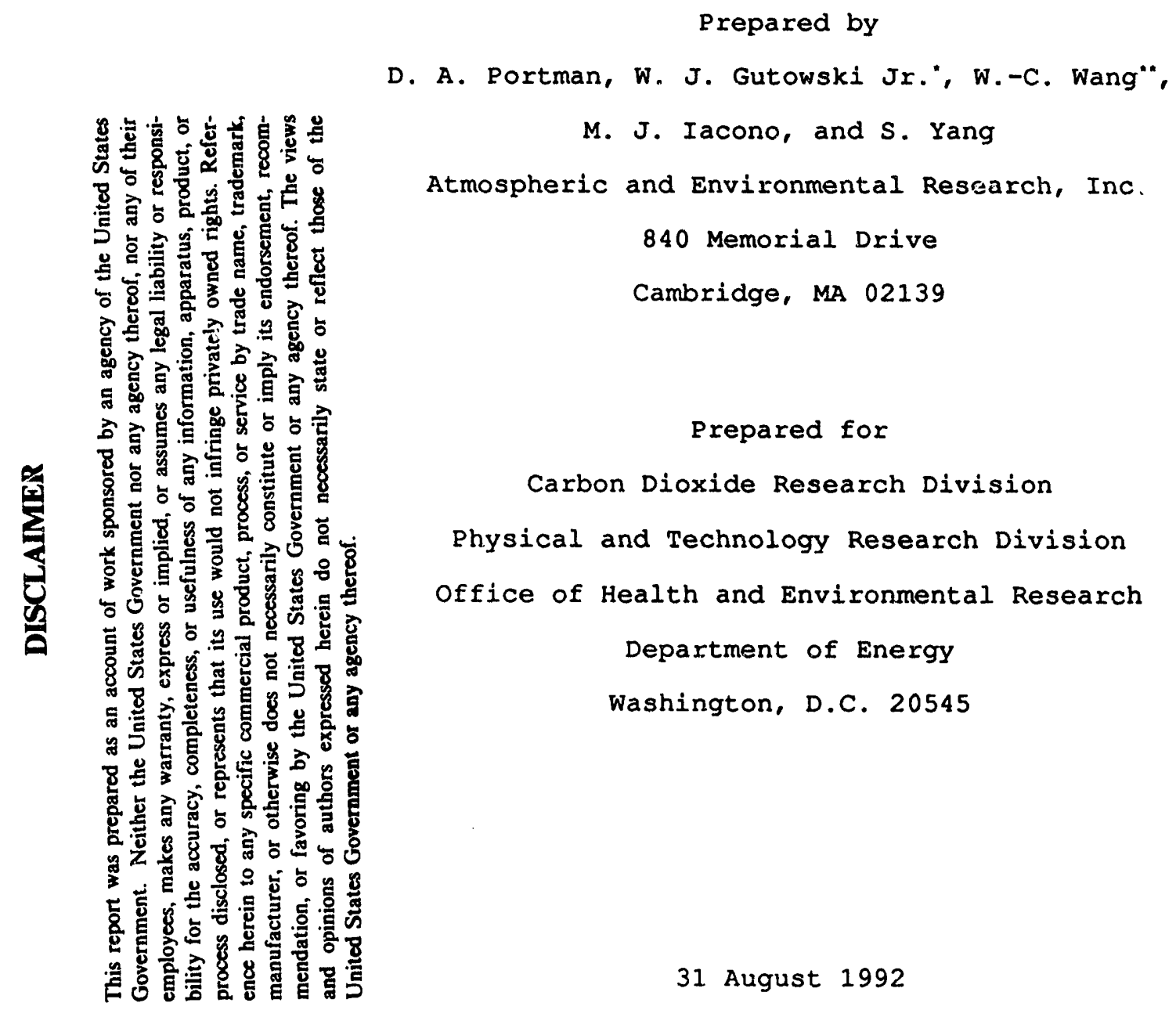

"Current affiliation: Department of Geologic and Atmospheric Sciences, Iowa State University, Ames, IA

"At Atmospheric Sciences Research Center, State University of New York, Albany, N.Y. 
This report summarizes work performed under grant DE-FG02-86ER60422 between 1 March 1986 and 31 August 1992. Included in the research program were three tasks:

I. GCM intercomparison and improvement.

II. Analysis of climate data and climate model statistics.

III. China project science coordination.

Work was carried out at Atmospheric and Environmental Research, Inc. (AER) and at the Atmospheric Sciences Research Center of the State University of New York at Albany (SUNYA). At SUNYA, work was performed under direction of Dr. Wei-Chyung Wang as subcontractor to AER. Highlights and accomplishments of the research program are summarized below with references. A list of project publications is presented in Appendix A.

\section{Task I: GCM Intercomparison and Improvement}

Four subtasks are described: atmosphere-ocean coupling, GCM simulated surface energy balance of $1 \mathrm{xCO}_{2}$ and $2 \mathrm{xCO}_{2}$, spectrai-to-grid point model comparison, and GCMs for regional climate study.

\section{A. Atmosphere-Ocean Coupling}

We explored the possibility of accelerating the convergence to statistical equilibrium of a seasonal climate model whose ocean is a simple mixed layer. The procedure developed involves reducing the thermal inertia of the ocean and increasing the frequency of the solar forcing cycle during an acceleratinn period. The procedure is simple to apply and can allow more extensive use of seasonal models for climate change studies.

Reference:

Gutowski, W. J., Jr. and G. Molnar, 1988. Accelerating the convergence of seasonal climate models with mixed layer oceans. J. Geophys. Res., 93, 1737-1744. 


\section{B. GCM Simulated Surface Energy Balance of $1 \mathrm{xCO}_{2}$ and $2 \mathrm{xCO}_{2}$}

We examined the surface energy balances simulated by GCMs at GFDL, GISS, and NCAR for climates with $1 \times \mathrm{CO}_{2}$ and $2 \mathrm{xCO}_{2}$. The surface enexgy balance enables us to diagnose differences between models of surface temperature climatology and sensitivity to dnubling $\mathrm{CO}_{2}$ in terms of the processes that control surface temperature. Our analysis compares the simulated balances by averaging the fields of interest over a hierarchy of spatial domains ranging from the entire globe down to regions a few hundred kilometers across. It was found that a better understanding of the hydrological cycle and how to simulate it appear to be especially important for improving regional climate modeling.

References:

Gutowski, W. J., Jr., D. S. Gutzler and W.-C. Wang, 1991. Surface energy balances of three general circulation models: Implications for simulating regional climate change. J. Climate, 4, 121-134.

Gutowski, W. J., Jr., D. S. Gutzler, D. A. Portman and W.-C. Wang, 1988. surface energy balance of three general circulation models: current climate and response to increasing atmospheric $\mathrm{CO}_{2}$. Technical Report 42, Carbon Dioxide Research Division, U.S. Department of Energy. DOE/ER/60422-H1, $119 \mathrm{pp}$.

\section{Spectral-to-Grid Point Model Intercomparison}

We compared climate simulations from two models that are identical except that one uses grid-point techniques and the other spectral techniques for the numerical treatment of atmospheric dynamics. Our purpose was not to determine which technique is better, but to indicate the dependence of climate simulation on model numerics. Simulations of a perpetual July were performed using spectral and grid-point dynamics codes coupled to the oregon state University model's two-iayer atmospheric physics. We found that diabatic 
heating, in the model tends to amplify differences resulting from the choice of numerical technique. Varying horizontal resolution also aiters model

climatology, but generally no more than switching from one numerical system to the other.

Our results suggest that there is an interplay between characteristics of the dynamics simulation and the tuning of parameterizations used in a model. The compensation that can occur (either deliberately or by accident) between shortcomings of model dynamics and physics when a model is tuned to give an acceptable current climate simulation may influence a model's sensitivity to forcing changes.

\section{Reference:}

Gutowski, W. J., Jr., M. J. Iacono, X.-Z. Liang and W. - C. Wang, 1990 . Simulating climate with two different numerical schemes. Technical Report 49, Carbon Dioxide Research Division, U. S. Department of Energy, $57 \mathrm{pp}$.

\section{GCMs for Regional climate Study}

(1) As an alternative means for evaluating regional climate variability, we fed tropical, $\mathrm{CO}_{2}$-doubling changes from GCMs into a hurricane model to determine changes in local, severe-rainfall characteristics. Usi ug these changes in a hydrological basin model, we found that global warming could negate most of the benefits of existing water management practice established for the basin.

Reference:

Gutowski, W. J., Jr., G. F. McMahon, S. S. Schluchter, and P. H. Kirshen, 1992. Effects of global warming on hurricane-induced flooding. J. Water Res. Plan. Man. (submitted, Appendix B) 
(2) We investigated possible impact of doubling $\mathrm{CO}_{2}$ on the zonal mean zondl winds and the angular momentum of the atmosphere using general circulation model output archived by the Goddard Institute for Space Studies, the National Center for Atmospheric Research, and the Geophysical Fluid Dynamics Laboratory. Comparisons among the three models of the difference in zonal mean zonal winds between $2 \mathrm{xCO}_{2}$ and $1 \mathrm{xCO}_{2}$ simulations indicate a common tendency when $\mathrm{CO}_{2}$ is doubled for winds to become more easterly in much of the tropics during June-July-August. Largely because of these tropical wind changes, decreases in the troposphere's relative angular momentum accompany a doubling of $\mathrm{CO}_{2}$ in all the model runs. Although the possibility of an anthropogenic effect on earth's rotation is noteworthy, any predictions must be regarded as tentative in light of the short-comings found in the model's zonal wind climatologies and the differences in their zonal mean responses.

Reference:

Rosen, R. D., and W. J. Gutowski Jr., 1992. Response of zonal winds and atmospheric angular momentum to a doubling of $\mathrm{CO}$. J. Climate (In press, Appendix C).

(3) The stationary wave activity flux (SWAF) derirod by Plumb is a useful diagnostic for understanding the three-dimensional features of sources, sinks, and propagation of the atmospheric quasi-stationary waves. We computed this flux using updated National Meteorological Center analyses and output of Geophysical Fluid Dynamics Laboratory and National Center for Atmospheric Research general circulation models. In general, we found that the models can simulate the major features of the SWAF, especially over regions where source forcing is strong. On a regional basis, however, differences appear from both model-observation and model-model comparisons, especially in the Southern Hemisphere. A comparison of model output between the control and doubled- $\mathrm{CO}_{2}$ runs indicated that weaker SWAF statistics occur for doubled- $\mathrm{CO}_{2}$. 
Referençe:

Yang, S. and W. J. Gutowski Jr., 1992. Atmospheric stationary wave activity flux and its change with $\mathrm{CO}_{2}$ doubling. (in preparation, Appendix D).

\section{Task 2: Analysis of Climate Data and Climate Model Statistics}

Five subtasks are described: proxy climate data reconstruction, climate data analysis/climate statistics, GCM/observational comparisons of regional/local climate, climate over arid/semiarid regions in U.S. and China, and regional climate in China during historical times.

\section{A. Proxy Climate Data Reconstruction}

(1) The 510-year, 120-station proxy precipitation records published by the State Meteorological Administration, the People's Republic of China were used to study the large-scale climate patterns, including the climate regions and inter-regional relationships. It was found that the climate patterns remain similar when the density and domain of the 120-station network are systematically reduced. It was also found that similar climate patterns are obtained when the statistical techniques of factor analysis and the principal component/cluster analysis are used. The climate patterns were found to be consistent with geophysical factors.

References:

Ronberg B. P. and W. C. Wang, 1987. Climate patterns derived from Chinese proxy precipitation records: An evaluation of the station networks and statistical techniques. J. Climatology, 7, 215-229.

(2) A comparative study of rainfall patterns over China between 18801979 and the period of the Little Ice Age (1600-1699) was performed. We used principal component analysis and cluster analysis to define the rainfull patterns from the precipitation proxy index published by the State Meteorological Administration, the People's Republic of China. Results suggest that the 
recent 100 years were wet compared with the Little Ice Age years, many of which were very dry.

\section{References :}

Ronberg, B. P. and W.-C. Wang, 1987. Rainfall patterns over China during the Little Ice Age and the recent hundred years. Proceedings of the Eleventh Climate Diagnostics Workshop, Illinois State Water Survey, University of Illinois, Champaign Illinois, octuber 14-17, 1986. U.S. Department of Commerce, PB87-175741, pp 152-156.

Wang, W.-C., B. Ronberg, and D. Portman, 1988. Climate patterns in China and the U. S. Proceedings of the Second Science Team Meeting of the United States of America Department of Energy and the People's Republic of China Academia Sinica Joint Research Program on $\mathrm{CO}_{2}$-Induced Climate Change. DOE/Conf-8708252.

(3) The Clear-Rain Records (Qing Yu Lu in Chinese) in the Beijing Palace Museum date back to 1724 and offer excellent data for climate study. We used the monthly numbers of rain days and of daytime rain-hours of the clear-Rain Records as well as the monthly temperature measurements of recent decades to reconstruct the historical summer temperatures in Beijing. The reconstruction technique was found to be an improvement of a similar procedure also developed for summer temperature reconstructions by the Institute of Geography, Chinese Academy of Sciences, the People's Republic of China.

References:

Wang, W.-C., D. A. Portman, G. Gong, P. Zhang, and T. R. Karl, 1992. Beijing summer temperatures since 1724. in Climate Since A.D. 1500, R. S. Bradley and P. D. Jones, eds., Routledge, London, pp 210-223. 


\section{B. Climate Data Analysis/Climate Statistics}

(1) Two long-term instrumental data bases containing meteorological observations from the People's Republic of China (PRC) were compiled in accordance with the joint research agreement signed by the United states Department of Energy and the PRC Chinese Academy of Sciences (CAS). CAS provided data of 265 stations, partitioned into networks of 60 and 205 stations. Together, these PRC data sets represent the most comprehensive, long-term instrumental Chinese climate data presently available.

Reference :

Tao, S., C. Fu, Z. Zeng, and Q. Zhang, 1991. Two long-term instrumental climatic data bases of the People's Republic of China. Prepared by D. P. Kaiser, Carbon Dioxide Information Analysis Center, Oak Ridge National Laboratory, Oak Ridge, Tennessee, ORNL/CDIAC-47, NDP-039, 198 pp.

(2) We used a bootstrap procedure to produce estimates of mean and variance of surface air temperature for a 260-station climate network in the People's Republic of China. Frequency distributions of the results suggest that neither the mean nor the median of these estimates is the best statistic for describing the temperature variability. Therefore, it was proposed that estimates of the mean be used as measures of both mean and variability of regional surface air temperature in china. Of each distribution of bootstrap values, the median (50th percentile) and the 10-90 percentile difference can be used to describe the mean temperature and temperature variability, respectively.

Reference :

Portman, D. A., W.-C. Wang, and Z. M. Zeng, 1991. Estima:ing climate variability over China. Proceedings of the Fifteenth Annual Climate Diagnostics Workshop National Climatic Data Center, NESDIS, NOAA, 
Asheville, North Carolina, October 29-November 2, 1990. U.S. Department of Commerce. pp. 390-395.

(3) We used the 1954-1983 surface temperature of 42 Chinese urban (average population $1.7 \times 10^{6}$ ) and rural (average population $1.5 \times 10^{5}$ ) station pairs to study the urban heat island effects. Despite the fact that the rural stations are not true rural stations, the magnitude of the heat islands was calculated to average $0.23^{\circ} \mathrm{C}$ over the 30 -year period with a minimum value during the 1964-1973 decade and a maximum value during the most recent decade (1974-1983). The urban heat islands were found to have seasonal dependence which varied considerably across the country and a strong regional dependence dominated by the Northern Plains. The changes in heat isiand intensity over three decades studied suggest a general increase in heat island intensity of about $0.1^{\circ} \mathrm{C}$, but this increase has not been constant in time.

\section{References:}

Wang, W.-C., Z.-M. Zeng and T.R. Karl, 1990. Urban heat islands in China. Geophys. Res. Lett., 17, 2377-2380.

(4) We conducted a detailed study of surface temperatures and urban bias in China's Northern Plains (NP), a low-lying and relatively flat region. Temperatures of climatological surface stations were examined using a statistical rank-score procedure that allows screening the data without knowing the station history information; time series found to exhibit large potential discontinuities (i.e., those introduced as a result of non-climatic factors such as observation schedule changes, instrument replacements, and station moves) were excluded from further analysis. A systematic sampling strategy was then employed for estimating the bias in annual and seasonal mean temperatures of 21 urban stations relative to 8 rural stations. In general, we found that temperatures of stations located near the most densely populated cities exhibit the largest magnitudes and trends of urban bias; these mag- 
nitudes, and trends are greates during spring and summer than during autumn and winter. Results of a comparison of trends between NP regional temperature time series and a time series of grid-point temperature anomalies taken from a widely-used, land-surface data set suggest that effects of the urban heat islands in China (and, by extension, in other parts of the developing world) may be more important than previously thought.

References:

Portman, D. A., 1992. Identifying and correcting urban bias in regional time series: Surface temperature in China's Northern Plains. J. Climate, (submitted, Appendix E).

(5) We explored the relationship between monthly tropical Chinese rainfall (TCR) and June-september Indian summer monsoor rainfall (ISMR) between 1954-1988. Results indicate that the TCR during May is a precursor of the ISMR.

Reference:

Yang, S., and W. J. Gutowski Jr., 1992. On the relationship between tropical Chinese rainfall and the Indian summer monsoon. J. Meteor. Soc. Japan, (accepted, Appendix F).

\section{GCM/Observational Comparisons of Regional/Local Climate}

(1) Important surface observations such as the daily maximum and minimum temperature, daily precipitation, and cloud ceilings often have localized characteristics that are difficult to reproduce with the current resolution and the physical parameterizations in state-of-the-art general circulation climate models (GCMs). Many of the difficulties can be partially attributed to mismatches in scale, local topography, regional geography and boundary conditions between models and surface-based observations. Therefore, we devised a method called climatological projection by model statistics (CPMS) and used 
it to relate GCM gridpoint free-atmosphere statistics, the predictors, to

these important local surface observations.

We found that even an early version of the oregon State University two-level atmospheric GCM (with prescribed sea surface temperature) produces freeatmosphere statistics that can, when standardized using the model's internal means and variances, closely approximate the observed iocal climate. Our results also indicate that the differences between the output of a ten-year GCM control run and the surface-based observations are often smaller than the differences between the observations of two ten-year periods. Thus, GCMs may already contain important climatological information which can be used to infer the local climate.

\section{References:}

Karl, T. R., W.-C. Wang, M. E. Schlesinger, R. W. Knight and D. A. Portman, 1990. A method of relating general circulation model simulated climate to the observed local climate. Part I: Seasonal statistics. J. Climate, $3(10), 1053-1079$.

(2) Two approaches were studied for comparing output of individual GCM gridboxes with local station observations near the surface and in the free troposphere. The first approach, proposed by Chervin, involves application of standard parametric statistical analysis and hypothesis testing procedures. i'he second approach is non-parametric in the sense that no ideal distributions are postulated a priori to ascertain significance of the difference between model gridboxes and local stations of the mean temperature or of the ratio of their temperature variances. Instead, station observations ase first subjected to a bootstrap technique and then used to define a unique set of distributions and confidence limits for each GCM gridbox.

We compared daily and seasonal gridbox temperatures simulated by the National Center for Atmospheric Research Community Climate Model (CCMl) with station temperatures at the surface, $850 \mathrm{mb}, 500 \mathrm{mb}$, and $300 \mathrm{mb}$ levels for 
three different areas in the United States. We found that although the CCM1 gridbox temperatures are (mostly) cooler than the station temperatures, they are equally variable. For all gridboxes, gridbox-to-station differences decrease with height and vary with time-of-year.

\section{References:}

Portman, D. A., W. -C. Wang, and T. R. Karl, 1992. Comparison of general circulation model and observed regional climates: Daily and seasonal variability. J. Climate, 5, 343-353.

Portman, D. A., W.-C. Wang, and T. R. Karl, 1990. A comparison of general. circulation model and observed regional climates: Daily and seasonal variability. Proceedings of the Fourteenth Annual Climate Diagnostics Workshop, Scripps Institution of Oceanography, University of Californic, San Diego, La Jolla, California, October 16-20, 1989. U.S. Department of Commerce, PB90-198573, pp. 282-288.

Portman, D. A., W.-C. Wang, and T. R. Karl, 1989. Regional climate characteristics: a comparison between observations and general circulation model statistics. Proceedings of the Thirteenth Annual Climate Diagnostics Workshop, Atmospheric cnd Environmental Research Inc., Cambridge, Massachusetts, October 31-November 4, 1988, U. S. Department of Commerce, PB89-178115, pp. 256-260.

\section{Climate over Arid/Semiarid Regions in U.S. and China}

(1) The observational data of temperature, humidity, clouds, and solar radiation reaching the surface were analyzed for two stations, Minqin and Tongliao, in desert regions of horthern China. The results suggest that the humidity and cloudiness were greater diring the wet year (1964) than during the dry year (1972), while there were no large differences in monthly mean temperature between these two years. We also found that there was an excellent 
correlation between the solar flux reaching the ground and amount of low clouds. The difference between the calculated and observed solar flux, which might reflect the contributions of clouds and aerosols, was also examined.

\section{Reference:}

Wang, W.-C., G. Shi, K. Li, and I. Xu, 1987. Climate and solar radiation characteristics over desert regions in northern China during a dry and a wet year. in Atmospheric Radiation Progress and Prospects. K. -N. Liou and $x$. Zhou, eds., Science Press, Beijing.

(2) In recent yea.s, the semi-arid reginn of northern China, which has total precipitation between 200 and $500 \mathrm{~mm}$, has shown signs of severe desertification. We used the 1951-1986 monthly precipitation measurements over semiarid regions in northern China to study fluctuations and relationships with the El Niño/Southern Oscillation (ENSO). Three main features were identified in all the station time series: a 2-3 year quasi-periodic fluctuation, a significant correlation between the precipitation fluctuation and ENSO with the former lagging the latter by 2-5 months, and a tendency for rainfall deficiency during ENSO years. These features are also evident from analysis of the proxy data during the last hundred years. Possible links between the precipitation fluctuation, the summer monsoon, the western Pacific subtropical high, and ENSO were explored.

Reference:

Wang, W.-C. and K. Li, 1990. Precipitation fluctuation over semiarid region in Northern China and the relationship with El Niño/Southern Oscillation. J. Climate, 3, 769-783.

\section{E. Regional Climate in China During H itorical Times}

A comparison of climate changes in China between $6000 \mathrm{yr}$. BP and the present with simulated $\mathrm{CO} 2$-doubling changes shows many similar 
characteristics, lending insight into the possible regional effects of global warming in China.

Reference:

Zhang, Y., and W.-C. Wang, 1990. The surface temperature in China during midholocene. Acta Geographica Sinica.

\section{Task 3: China Project Coordination}

This task primarily concerns coordination of the scientific tasks among the US and Chinese scientists participating in the US/DOE-PRC/CAS joint research on the greenhouse effect. Effort was also spent, however, for coordinating and hosting the DOE sponsored Second GCM Intercomparison Workshop at AER, 7-8 July 1988. The 24 participants attending this meetinc came from six countries and represented various government, university and private industry groups that oversee the development and analysis of GCMs. The workshop was successful and laid the foundation for future international participation in studies aimed at understanding and further improving the GCMs .

Each year, at least one meeting was held allowing scientists from both the United States and China to convene and discuss progress and results of the joint research. Because the major research goals of the US/DOE-PRC/CAS joint program had been met, the meeting held on the SUNY at Albany campus from 30 September-2 October 1991 was more elaborate than past meetings. Prominent scientists and researchers from both the United States and China participated. Among the Chinese delegation of 19 scientists were representatives from the CAS' Institute of Atmospheric Physics and the Institute of Geography. Project coordination also involved integrating the individual tasks and monitoring their progress to accomplish project objectives. For the most part, this coordination was handled by Dr. W. - C. Wang, the US/DOE-PRC/CAS chief scientist. He worked with Mike Riches of DOE and Chen Panqin of CAS, the U.S. and Chinese project managers, respectively, and with the other 
scientișts to streamline the tasks and to discuss the objectives and schedules for the four research areas outlined by Koomanoff et al. (1988) and Riches et a1. (1992).

From 8-21 February 1992, Dr. Wang made a trip to China to discuss future technical tasks with CAS.

References:

Cess, R. D. et al., 1991. Interpretation of snow-climate feedback as produced by 17 general circulation models. Science. 253, 888-892.

Gutowski, W. J., Jr., G. I. Potter and M. R. Riches, 1988. DOE model intercomparison workshop II. Bull. Am. Meteor. Soc., 69, 1453-1454.

Koomanoff, F. A., D. Ye, J. Zhao, M. R. Riches, W.-C. Wang and S. Tao, 1988. The United States' Department of Energy and the People's Republic of China's Chinese Academy of Sciences joint research on the greenhouse effect. Bul1. Amer. Met. Soc., 69, 1301-1308.

Riches, M. R., Zhao J., W.-C. Wang, and Tao, S., 1992. The United States' Department of Energy and the People's Republic of China's Academy of Sciences joint research on the greenhouse effect: 1985-1990 research progress. Bull. Amer. Met. Soc. 73, 585-596. 
Appendix A

List of Project Publications 
Below is a summary of journal articles, technical reports, and conférénce abstracis published under grant DE-FG02-86ER60422. Items are listed alphabetically by first author.

Ces:, R. D. et al., 1991. Interpretation of snow-climate feedback as produced by 17 general circulation models. Science. 253, 888-892.

Gutowski, W. J., Jr. and G. Molnar, 1988. Accelerating the convergence of seasonal climate models with mixed layex oceans. J. Geophys. Res., 93, $1737-1744$.

Gutowski, W. J., Jr., D. S. Gutzler, D. A. Portman and W.-C. Wang, 1988. Surface energy balance of three general. circulation models: current: climate and response to increasing atmospherio $\mathrm{CO}_{2}$. Technical Report 42, Carbon Dioxide Research Division, U.S. Department of Energy. $\mathrm{DOE} / \mathrm{ER} / 60422-\mathrm{H} 1,119 \mathrm{pP}$.

Gutowski, W. J., Jr., G. L. Potter and M. R. Riches, 1988. DOE model intercomparison workshop II. Bull. Am. Meteor. Soc., 69, 1453-1454.

Gutowski, W. J., Jr., M. J. Iacono, X.-Z. Liang and W.-C. Wang, 1990 . Simulating climate with two different numerical schemes. Technical Report 49, Carbon Dioxide Research Division, U. S. Department of Energy, $57 \mathrm{pp}$.

Gutowski, W. J., Jr., D. S. Gutzler and W.-C. Wang, 1991. Surface energy balances of three general circulation models: Implications for simulating regional climate change. J. Climate, 4, 121-134.

Gutowski, W. J., Jr., G. F. McMahon, S. S. Schluchter, and P. H. Kirshen, 1992. Effects of global warming on hurricane-induced flooding. $J$. 
Water Res. Flan. Man. (submitted, Appendix B)

Karl, T. R., W.-C. Wang, M. E. Schlesinger, R. W. Knight and D. A. Portman, 1990. A method of relating general circulation model simulated climate to the observed local climate. Part I: Seasonal statistics. J. Climate, $3(10), 1053-1079$.

Koomanoff, F. A., D. Ye, J. Zhao, M. R. Riches, W.-C. Wang and S. Tao, 1988. The United States' Department of Energy and the People's Republic of China's Chinese Academy of sciences joint research on the greenhouse effect. Bull. Amer. Met. Soc., 69, 1301-1308.

Portman, D. A., 1992. Identifying and correcting urban bias in regional time series: Surface temperature in China's Northern Plains. J. Climate, (submitted, Appendix E).

Portman, D. A., W.-C. Wang, and T. R. Karl, 1989. Regional climate characteristics: a comparison between observations and general circulation model statistics. Proceedings of the Thirteenth Annual Climate Diagnostics Workshop, Atmospheric and Environmental Research Inc., Cambridge, Massachusetts, October 31-November 4, 1988, U. S. Department of Commerce, PB89-178115, pp. 256-260.

Portman, D. A., W.-C. Wang, and T. R. Karl, 1990. A comparison of general circulation model and observed regional climates: Daily and seasonal variability. Proceedings of the Fourteenth Annual Climate Diagnostics Workshop, Scripps Institution of Oceanography, University of California, San Diego, La Jolla, California, October 16-20, 1989. U.S. Department of Commerce, PB90-198573, pp. 282-288. 
Portman, D. A., W.-C. Wang, and Z. M. Zeng, 1991. Estimating climate variability over China. Proceedings of the Fifteenth Annual Climate Diagnostics Workshop National Climatic Data Center, NESDIS, NOAA, Asheville, North Carolina, October 29-November 2, 1990. U.S. Department of Commerce. pp. 390-395.

Portman, D. A., W.-C. Wang, and T. R. Karl, 1992. Comparison of general circulation model and observed regional climates: Daily and seasonal variability. J. Climate, 5, 343-353.

Riches, M. R., zhao J., W.-C. Wang, and Tao, S., 1992. The United States' Department of Energy and the People's Republic of China's Academy of Sciences joint research on the greenhouse effect: 1985-1990 research progress. Bull. Amer. Met. Soc. 73, 585-596.

Rosen, R. D., and W. J. Gutowski Jr., 1992. Response of zonal winds and atmospheric angular momentum to a doubling of $\mathrm{Co}$. J. Climate (In press, Appendix C).

Ronberg, B. P. and W.-C. Wang, 1987. Rainfall patterns over China during the Little Ice Age and the recent hundred years. Proceedings of the Eleventh Climate Diagnostics Workshop, Illinois State Water Survey, University of Illinois, Champaign Illinois, october 14-17, 1986. U.S. Department of Commerce, PB87-175741, pp 152-156.

Ronberg B. P. and W. - C. Wang, 1987. Climate patterns derived from Chinese proxy precipitation records: An evaluation of the station networks and statistical techniques. J. Climatology, 7, 215-229.

Tao, S., C. Fu, Z. Zeng, and Q. Zhang, 1991. Two long-term instrumental climatic data bases of the People's Republic of China. Prepared by D.P. 
Kaiser, Carbon Dioxide Information Analysis Center, Oak Ridge National Laboratory, Oak Ridge, Tennessee, ORNL/CDIAC-47, NDP-039, 198 pp.

Wang, W. C. and K. Li, 1990. Precipitation fluctuation over semiarid region in Northern China and the relationship with El Niño/Southern Oscillation. J. Climate, 3, 769-783.

Wang, W. -C., G. Shi, K. Li, and L. Xu, 1987. Climate and solar radiation characteristics over desert regions in northern China during a dry and a wet year. in Atmospheric Radiation Progress and Prospects. K. -N. Liou and $x$. Zhou, eds., Science Press, Beijing.

Wang, W.-C., B. Ronberg, and D. Portman, 1988. Climate patterns in China and the U. S. Proceedings of the Second Science Team Meeting of the United States of America Department of Energy and the People's Republic of China Academia Sinica Joint Research Program on $\mathrm{CO}_{2}$-Induced Climate Change. DOE/Conf -8708252 .

Wang, W. C., Z.-M. Zeng and T.R. Karl, 1990. Urban heat islands in China. Geophys. Res. Lett., 17, 2377-2380.

Wang, W.-C., D. A. Portman, G. Gong, P. Zhang, and T. R. Karl, 1992. Beijing summer temperatures since 1724. in Climate since A.D. 1500, R. S. Bradley and P. D. Jones, eds., Routledge, London, pp 210-223.

Yang, S., and W. J. Gutowski Jr., 1992. On the relationship between tropical Chinese rainfall and the Indian summer monsoon. J. Meteor. Soc. Japan, (accepted, Appendix F).

Yang, S. and W. J. Gutowski Jr., 1992. Atmospheric stationary wave activity flux and its change with $\mathrm{CO}_{2}$ doubling. (in preparation, Appendix D). 
Zhang, Y., and W.-C. Wang, 1990. The surface temperature in China during mid- holocene. Acta Geographica Sinica.

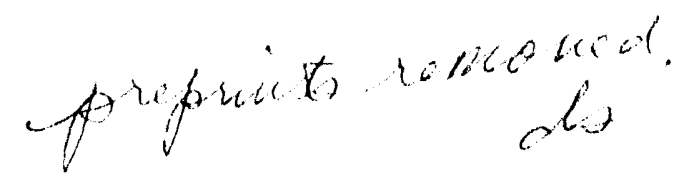



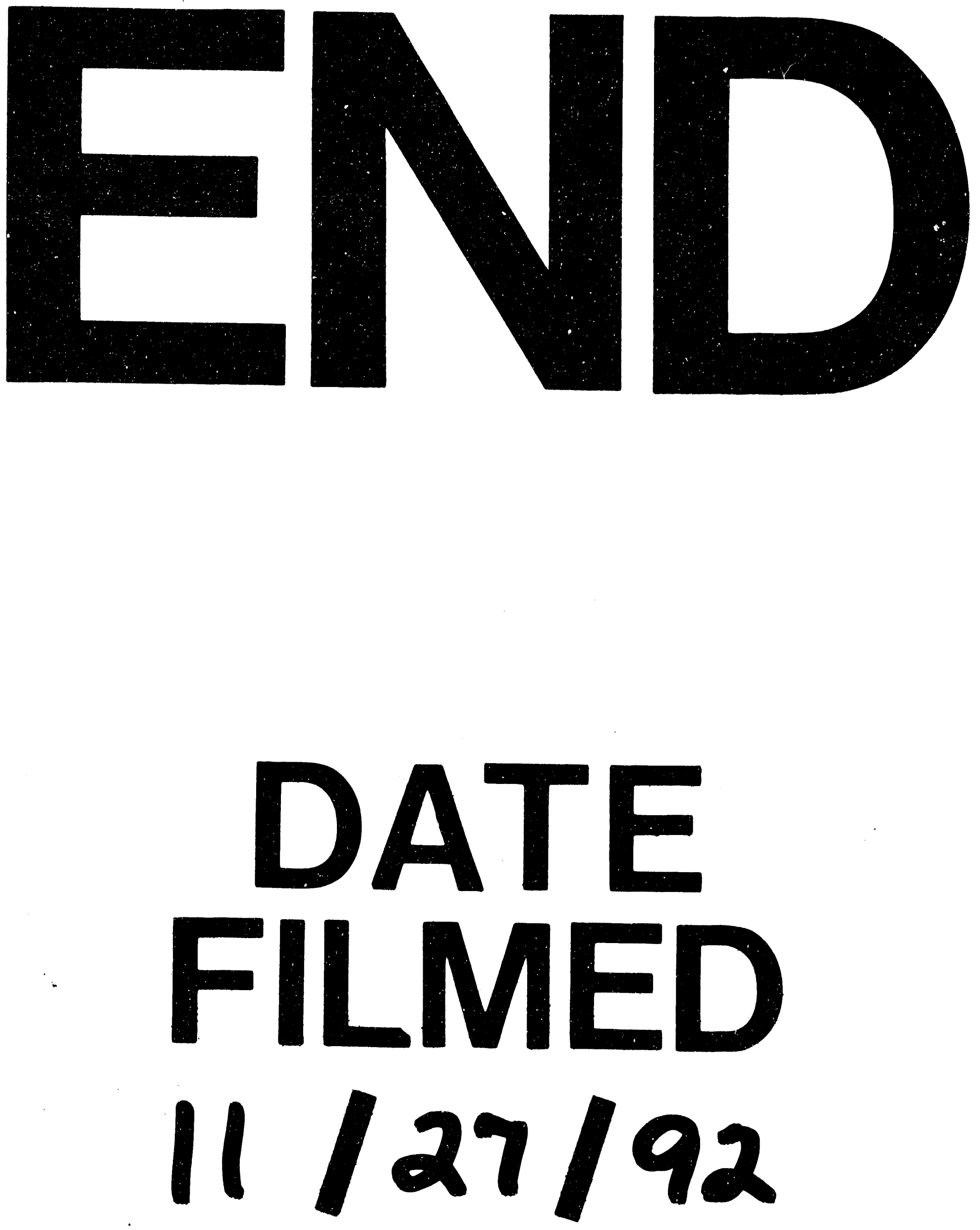
